\title{
El aeropuerto como dispositivo disciplinar para el control de la movilidad*
}

\section{Resumen}

Desde los atentados del 11-S, los aeropuertos se han convertido en unos dispositivos de control y vigilancia únicamente comparables con las cárceles de máxima seguridad. Por ello, la mayor parte de los estudios dedicados a los mismos han experimentado una progresiva afinidad con los trabajos de Michel Foucault y Paul Virilio, en los que la arquitectura es caracterizada como técnica paradigmática para organizar el espacio (compartimentación) y el tiempo (distribución de secuencias) con el fin de lograr la individualización, clasificación, ordenación y normalización de sus usuarios.

Este artículo tiene por objetivo identificar las principales estrategias espaciales mediante las cuales los aeropuertos implementan el control disciplinar de los pasajeros, con independencia de su estilo formalcompositivo, su estética sociofenomenológica y/o la introducción de dispositivos electrónicos de vigilancia. Para ello, desarrollamos una metodología basada en el análisis gráfico (en planta y sección) de cinco aeropuertos de pequeño tamaño proyectados en un mismo ámbito territorial (estatal) y en un lapso homogéneo con el doble objetivo de que no haya cambios sustanciales en la legislación aplicable ni en el desarrollo de nuevas tecnologías de edificación, control y vigilancia que puedan afectar al diseño básico de su organización espacial.

Los resultados obtenidos muestran la presencia constante de una organización espacial lineal y jerárquica consistente en la sucesión "entrada-facturación-control de personas-shopping-embarque" con independencia de cualquier otra posible consideración estética, fenomenológica o social del espacio diseñado. Ello se opone a aquellos análisis realizados en las dos últimas décadas que priman el carácter rizomático, conectivo y no-jerarquizado del espacio aeroportuario frente a su segmentarización y jerarquización disciplinar. El artículo concluye remarcando el carácter totalitario que ha adquirido el control de la movilidad (aérea) en el siglo XXI.

\author{
Jorge León Casero \\ Doctor en Historia \\ Profesor interino de la Universidad \\ de Zaragoza, España. \\ Correo electrónico: jleon@unizar.es \\ ำ orcid.org/0000-0002-3723-1123 \\ Google Scholar
}

Recibido: diciembre 10 de 2018

Aprobado: marzo 25 de 2021

Palabras clave:

arquitectura aeroportuaria, control de personas, Michel Foucault, Paul Virilio, vigilancia.

\footnotetext{
* El presente artículo es un resultado del proyecto de investigación "Racionalidad económica, ecología política y globalización: hacia una nueva racionalidad cosmopolita". Programa Estatal Proyectos 1+D Retos de la Investigación del Ministerio de Ciencia, Innovación y Universidades, Gobierno de España. Ref.: PID2019-109252RB-I00.
} 


\section{The airport as a disciplinary device for mobility control}

\begin{abstract}
Since the 9/11 attacks, airports have become control and surveillance devices only comparable to maximum security prisons. For this reason, most of the studies dedicated to airports have experienced a progressive affinity with the works of Michel Foucault and Paul Virilio in which architecture is characterized as a paradigmatic technique to organize space (compartmentalization) and time (distribution of sequences) in order to achieve the individualization, classification, ordering and normalization of the users.
\end{abstract}

This article aims at identifying the main spatial strategies through which airports implement disciplinary control of passengers independently of their formal-compositional style, their sociophenomenological aesthetics and/or the introduction of electronic surveillance devices. To do this, a methodology based on the graphic analysis (ground plan and section) of five small airports projected in the same territorial area (State) and in a homogeneous time period was developed with the double objective of not having substantial changes in the legislation applicable or in the development of new building, control and surveillance technologies that may affect the basic design of their spatial organization.

The results obtained show the constant presence of a linear and hierarchical spatial organization consisting of the succession "entrycheck-in-control of people-shopping-boarding" independently of any other possible aesthetic, phenomenological or social consideration of the designed space. This is opposed to those analyzes carried out in the last two decades that prioritize the rhizomatic, connective and non-hierarchical character of the airport space over its segmentation and disciplinary hierarchy. The article concludes by highlighting the totalitarian character that control of (air) mobility has acquired in the 21 st century.
Key words: airport architecture, Michel Foucault, Paul Virilio, control of people, surveillance. 


\section{Introducción}

Según Paul Virilio, "la arquitectura es más que un conjunto de técnicas diseñadas para resguardarnos de la tormenta" (Virilio, 1984, p. 24). Concretamente, "es un instrumento de medición [...] capaz de organizar el espacio y el tiempo de una sociedad" (p. 25). En este sentido, la arquitectura es la técnica o dispositivo espacial necesario para producir orden público a través del control, vigilancia y establecimiento de los protocolos y secuencias obligatorios para el desplazamiento de personas y/o mercancías.

Buen ejemplo de ello es que justo en el momento en que el Estado francés iniciaba a mediados del siglo XVIII la construcción de un nuevo sistema de infraestructuras viarias que atravesaba todo su territorio, el oficial de policía Guillaute afirmaba que "el orden público reinará si tenemos cuidado de distribuir nuestro tiempo y espacio humanos entre la ciudad y el campo mediante una estricta regulación del tránsito" (Virilio, 2006, p. 43). Dado que según la teoría dromológica desarrollada por Virilio "la calle es tráfico" (p. 33), este último hace suya la famosa frase de Goebbels: "quien puede conquistar las calles, también conquista el Estado" (p. 30), concluyendo finalmente que "el auge del totalitarismo va de la mano con el desarrollo del control del Estado sobre la circulación de las masas" (p. 41).

De cara a este control, el Estado francés desarrolló junto a su sistema viario la que sería la tipología arquitectónica paradigmática del siglo XVIII: las aduanas. Concretamente, se planificó toda una red estatal de las mismas a lo largo del territorio francés, encargándose de su diseño el arquitecto Claude-Nicolas Ledoux, autor del conocido proyecto para la ciudad-fábrica de Les Salines de Chaux, comentado por Michel Foucault como uno de los precedentes arquitectónicos del panóptico de Bentham (Figura 1). Diseñado de tal modo que el vigilante puede ver fácilmente a todos los vigilados sin que estos sepan 
nunca si les están observando efectivamente, el principal efecto del panóptico radica en "inducir en el detenido un estado consciente y permanente de visibilidad que garantiza el funcionamiento automático del poder" (Foucault, 2005, pp. 203-205).
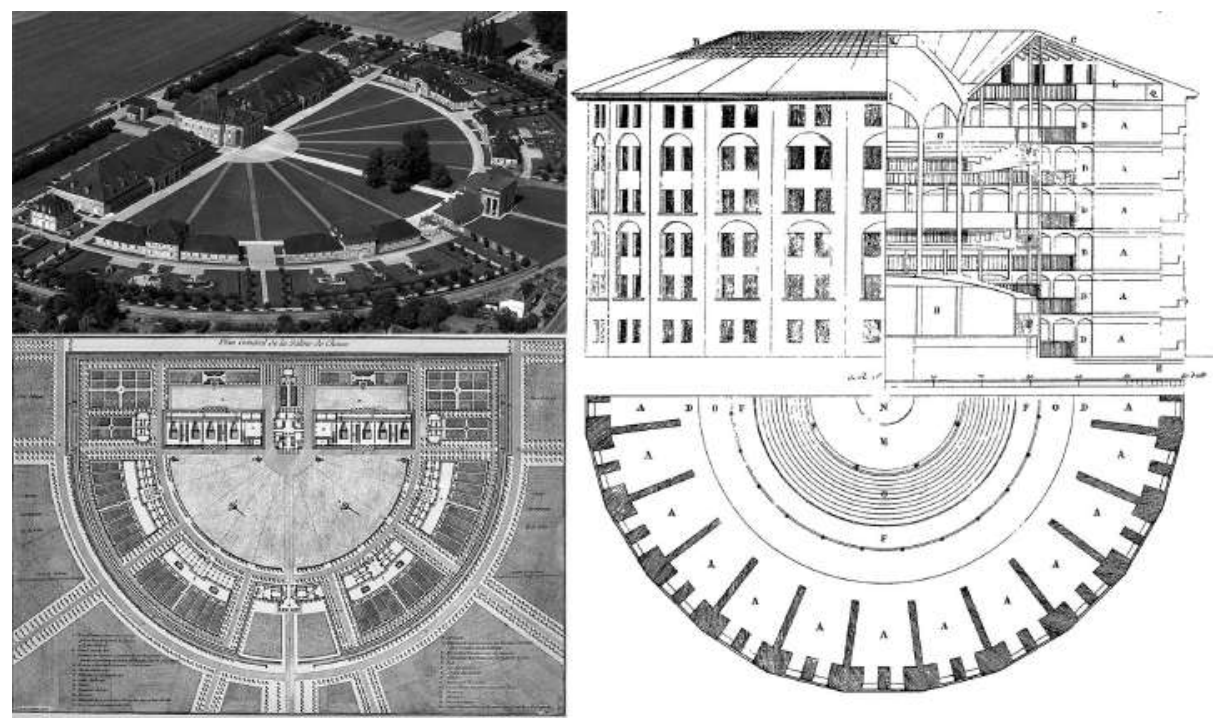

Figura 1. Comparación en planta y sección entre Les Salines de Chaux (izquierda) y el Panóptico de Jeremy Bentham (derecha), dibujado por Willey Reveley, 1791.

Por su parte, el proyecto "mitad ciudad - mitad fábrica" de Ledoux interesó a Foucault porque "a medida que aumentan el número de los obreros y la división del trabajo, las tareas de control se hacen más necesarias y más difíciles" (Foucault, 2005, p. 179). Debido a ello, el panoptismo se configura como el leitmotiv que condiciona toda la configuración formal del proyecto de cara a poder seguir garantizando las tareas de control que exige la nueva escala 
de producción. En todos los casos —aduana, cárcel y fábrica—, la finalidad de la arquitectura consiste en garantizar el control de la conducta y la movilidad de sus usuarios en aquellos enclaves que se consideran clave para el control general del (territorio del) Estado.

El presente artículo tiene por objetivo mostrar que en un mundo globalizado como el actual, la tipología arquitectónica paradigmática para el control del tráfico de personas ya no son únicamente las aduanas previstas para el tráfico terrestre y/o marítimo, sino las diseñadas para el aéreo: los aeropuertos, "última puerta de acceso al Estado [cuya función principal consiste en] separar a los enfermos o a los sospechosos" (Virilio, 1984, p. 12).

A este respecto, resulta importante resaltar que mientras que en los siglos XVIII y XIX el resto de tipologías urbanísticas y arquitectónicas para el control de la población (escuelas, hospitales, bibliotecas o fábricas) seguían los principios desarrollados por las prisiones panópticas, Virilio (1984) nos recuerda que "cuando los franceses construyeron sus 'prisiones de máxima seguridad' utilizaron las puertas magnéticas que los aeropuertos habían usado durante años [...] El equipamiento que aseguraba la máxima libertad al viajar formaba parte del sistema carcelario" (p. 14), antes incluso de que lo utilizasen las propias cárceles.

Desde los ataques terroristas del 11 de Septiembre esta situación no ha hecho más que incrementarse exponencialmente (Carter, 2001-02), hasta el punto de que a partir de entonces "las medidas antiterroristas convirtieron el aeropuerto en un entorno controlado electrónicamente que solo rivaliza con la prisión de máxima seguridad" (Gordon, 2004, p. 238). A consecuencia de ello, los principales trabajos académicos sobre aeropuertos publicados desde entonces comenzaron a realizarse desde una perspectiva mucho más próxima a la que habían mantenido Foucault y Virilio respecto de la arquitectura, marcando 
de este modo una neta diferencia con las aproximaciones epistemológicas previas al 11-S, consistentes en enfoques de tipo histórico-positivista (Leary, 1995), estilístico-formalista (Blow, 1991; Zukowsky, 1996; Edwards, 1998) o filosófico-antropológicos (Augé, 1995), que quedaron rápidamente obsoletas.

El presente artículo mantiene que esta relación de fondo, existente entre la arquitectura de prisiones y la de aeropuertos, estriba en que ambas obedecen a una concepción de la arquitectura como técnica paradigmática del poder disciplinar. Según Foucault, la cuestión clave que diferencia el funcionamiento disciplinar del poder respecto de una concepción soberana del mismo, radica en que su objetivo ya no consiste simplemente en castigar determinadas acciones contrarias a una ley concebida como expresión de la voluntad del sujeto soberano, sino que todos sus esfuerzos se concentran en producir un determinado tipo de conducta en los individuos gobernados.

En palabras del mismo Foucault (2005), "hay que cesar de describir siempre los efectos de poder en términos negativos: 'excluye', 'reprime', 'rechaza', 'censura', 'abstrae', 'disimula', 'oculta'. De hecho, el poder produce; produce realidad; produce ámbitos de objetos y rituales de verdad" (p. 198). A este respecto, la arquitectura sería uno de los principales "objetos" que establecen esos "rituales de verdad" en sus usuarios. Concretamente, el empleo disciplinar de la arquitectura queda definido por cinco funciones básicas, según las cuales:

1. Analiza, descompone a los individuos, los lugares, los tiempos, los gestos, los actos y las operaciones.

2. Clasifica los elementos así identificados en función de objetivos determinados.

3. Establece las secuencias o las coordinaciones óptimas.

4. Fija los procedimientos de adiestramiento progresivo y control permanente.

5. Distingue entre quienes serán calificados como ineptos e incapaces y los demás [...] Normal y anormal. (Foucault, 2006, p. 75) 
En el caso de los aeropuertos, el desarrollo tecnológico de las últimas décadas ha permitido "intensificar la vigilancia del movimiento a través de formas de monitorización combinadas" (Adey, 2004, p. 1365)', si bien el diseño arquitectónico del espacio continúa jugando un papel clave tanto en el control de los flujos de pasajeros, como en su normalización, análisis, clasificación y establecimiento de secuencias ${ }^{2}$. Las nuevas técnicas digitales de vigilancia por monitorización pueden haber puesto en crisis el principio panóptico de la arquitectura disciplinar, pero en modo alguno el resto de características que definen su funcionamiento, pues el diseño arquitectónico de los actuales aeropuertos continúa estableciendo las secuencias y rituales en los que se basa el filtrado de los flujos de pasajeros que los atraviesan (Lyon, 2001, 2003). Dichas secuencias son precisamente las que transforman "los movimientos globales de los viajes internacionales en la escala local de la actividad de la terminal" (Adey, 2002, p. 500), si bien existen distintas interpretaciones respecto al modo concreto en que lo hacen.

La primera de ellas ha sido desarrollada por Peter Adey (2007b, 2008c, 2009, 2010) de forma sistemática durante las dos últimas décadas. Si bien Adey reconoce que "en los últimos años se han encontrado en los aeropuertos las formas más diversas de vigilancia" (Adey, 2002, p. 500), ha negado sistemáticamente que dicha vigilancia y control propia del espacio aeroportuario conlleve una normalización o disciplinarización de los pasajeros al modo de la descrita por Foucault. En su lugar, el geógrafo londinense opina que "los aeropuertos definen estos espacios como libres, vacíos de poder y relaciones sociales, [es decir] abiertos a la movilidad" (Adey, 2004, p. 1365). Además, frente al ataque realizado por

\footnotetext{
${ }^{1}$ A este respecto, merecen una especial atención los nuevos smart airports o airports 3.0, definidos en virtud de "tres transformaciones clave: 1. Orientaciones experimentales derivadas del despliegue de las nuevas tecnologías de la información; 2. Una ingeniería empresarial experimental de mundos de consumo, o worlding; y 3 . Uso del tiempo de viaje orientado a un mundo de innovación infinita" (Elliot y Radford, 2015, p. 1063). ${ }^{2}$ Concretamente, la secuencia que se debe cumplir inexorablemente con independencia del tamaño y/o diseño formal propuesto por los arquitectos es — desde el punto de vista de las salidas-: entrada-facturación de equipaje-control de pasajeros-control de pasaportes (en caso de vuelos internacionales)-shopping libre de impuestos-embarque.
} 
otros investigadores que critican el espacio aeroportuario por considerar que promueven una "falta de identidad" (Augé 1995; Castells 1996), Adey insiste en que "las posibilidades de movilidad de los aviones" son capaces de dar lugar a un nuevo tipo de "pertenencia local y nacional" (Adey, 2006).

Según Adey, si bien los aeropuertos seguirían siendo auténticas máquinas para la vigilancia y control de los movimientos de las personas, el tratamiento espacial de los mismos ya no estaría orientado a analizar, clasificar y normalizar a los individuos de un forma jerárquica, sino que en la actualidad sería posible compaginar las necesidades de vigilancia y control con una concepción del espacio descrita como un "contexto afectivo-situacional" que mezcla continuamente "cálculo e indeterminación" (Adey, 2008a, p. 438).

Se desarrolla de este modo una concepción de los aeropuertos como dispositivos biopolíticos que fomentan la interrelación social mediante la generación de afectos, hasta el punto de considerarse espacios óptimos para un uso "familiar, hogareño y social [ideal para] fomentar prácticas corporales" (Adey, 2007a, p. 417). Además, gracias a que el control de los pasajeros puede realizarse mediante las nuevas tecnologías digitales de video-vigilancia y monitorización, el diseño arquitectónico podría volver a recuperar un grado de libertad mucho mayor para el establecimiento de las visuales de los espacios diseñados, de modo que los modernos aeropuertos 3.0 habrían sustituido el principio panóptico por una variada multiplicidad de lo que Adey denomina "prácticas visuales", concebidas para "inculcar inspiraciones, creencias y mensajes específicos en el usuario del aeropuerto" (Adey, 2008b, p. 29).

Como reacción directa al punto de vista mantenido por Adey, la segunda interpretación ha vuelto a insistir en el carácter específicamente disciplinarnormativo de los aeropuertos, llegándolos a considerar paradigmas postmodernos no únicamente en la vigilancia y control de las personas, sino 
también en la normalización de los individuos. Entre ellos, Aharon Kellerman afirma que los distintos espacios aeroportuarios proyectados por ingenieros y arquitectos deberían ser entendidos como "espacios de expresiones claramente explícitas de varias autoridades [que] bajo un régimen autoritario, promueven la pérdida de identidad de los cuerpos [disembodying] de los pasajeros" (Kellerman, 2008, p. 161)3 , desarrollando de este modo el planteamiento mantenido previamente por Wolf (2001), según el cual "los aeropuertos son tanto autoritarios [authoritarian] —emiten órdenes que deben obedecerse automáticamente - como autoritativistas [authoritative] —emiten reglas y regulaciones bien explicadas—" (p. 975).

Junto a Kellerman, las investigaciones más recientes han insistido una vez más en las críticas a Adey, ya sea concibiendo el espacio aeroportuario como "transhistórico, desprovisto de pasado, y únicamente apto para el consumo de un viajero solitario" (Sharma, 2017, p. 50), calificando sus consecuencias sobre la psique de los individuos como "impactos deshumanizantes de una frontera tecnificada y securitizada [que] generan y privilegian un tipo particular de sujeto ético: el individuo atomizado temporalmente suspendido" (Bulley, 2017, p. 217), o mostrando su funcionamiento "como lugar pedagógico que educa según un orden jerárquico" (Aaltola, 2005, p. 261) a la vez que "como lugar de intercambio comercial sin encuentros humano" (Crang, 2002, p. 569).

Frente a estas dos grandes interpretaciones claramente enfrentadas entre sí, la tercera línea de interpretación del espacio aeroportuario moderno aglutina una gran cantidad de propuestas marginales y/o alternativas que tratan de concebir el mismo mediante aproximaciones etnográficas y estéticas, ya sea aplicando

\footnotetext{
${ }^{3}$ Esta multiplicidad de dispositivos autoritarios presentes en la organización espacial de los aeropuertos a la que se refiere Kellerman, se subdividiría en 5 categorías principales: autoridades políticas, medioambiente, operaciones, flujos y socialidades. A su vez, la categoría de autoridades políticas estaría compuesta por los niveles "internacional, nacional, local y comercial"; la categoría medioambiente por "arquitectura, instalaciones y señalización"; la categoría operaciones por "funciones, control y vigilancia"; la categoría flujos por "terrestres y aéreos"; y finalmente la categoría socialidades por "descorporalización y dialéctica" (Kellerman, 2008, p. 167).
} 
el concepto de heterotopía de Foucault (Christiansen, 2010) o el "no-lugar" de Marc Augé junto a la noción de esfera-espuma de Peter Sloterdijk (Urry et al., 2016). Dentro de esta línea que podríamos denominar socioestética, resulta especialmente relevante la relación que algunos investigadores han establecido entre "estética" y "satisfacción". Concretamente, según los investigadores Moon et al. (2016), "la estética de las instalaciones es el componente más fuerte del entorno físico del aeropuerto para generar satisfacción" (p. 749), de modo que un entorno estéticamente satisfactorio sería la principal causa generadora de una sensación de seguridad en los individuos capaz de promover conductas abiertas, sociales y pacíficas.

En último lugar, la cuarta aproximación presente en la actual literatura científica referente al diseño aeroportuario radicaría en una lectura estilísticoformalista que ha eludido entrar en diálogo con la obra foucaultiana. Basada exclusivamente en el análisis de las características formales que permiten identificar los aeropuertos proyectados como parte de un determinado estilo o autoría arquitectónica (Pascoe, 2001; Pearman, 2004; Díaz, 2014), resulta cuanto menos sintomático el hecho de que algunos de los primeros aeropuertos diseñados en la década del treinta ${ }^{4}$ hayan sido analizados según categorías prácticamente idénticas a las utilizadas para el análisis de las primeras ciudades-aeropuerto diseñadas en el siglo $X X^{5}$, si bien tanto la escala, como las relaciones que se establecen entre sus partes y el modo de funcionamiento de cada una de estas tipologías no tienen en realidad nada que ver unas con otras.

\footnotetext{
${ }^{4}$ Concretamente, nos referimos a los aeropuertos de Madrid-Barajas, Paris-Le Bourget, Dublín-Collinstown y Berlin-Tempelhof estudiados por Díaz (2014).

${ }^{5}$ Los megaaeropuertos a los que nos referimos son el aeropuerto internacional de Kansai diseñado por Renzo Piano y el aeropuerto Chek Lap Kok de Hong Kong diseñado por Norman Foster, ambos analizados por Pearman (2004).
} 


\section{Metodología}

El presente artículo analiza gráficamente cinco aeropuertos españoles de pequeña escala con el objetivo de mostrar el carácter netamente disciplinar de la arquitectura aeroportuaria con independencia de su estilo formal, su estética socioespacial (y/o antropológica), la introducción de dispositivos electrónicos de vigilancia y la escala de las terminales. A este respecto, el gran tamaño y complejidad programática que los aeropuertos han adquirido durante las últimas décadas ha promovido que una gran parte de investigadores haya dejado de aproximarse a sus análisis desde las categorías gráficas propias de la disciplina arquitectónica para pasar a hacerlo desde un punto de vista que los entiende como ciudades, aplicándoles de este modo categorías y conceptos propios de la disciplina jurídico-urbanística (Gottdiener, 2001; Aaltola, 2005; Fuller y Harley, 2005; Kasarda, 2008; Hirsh, 2016).

Como consecuencia, la metodología de análisis de los aeropuertos internacionales de gran escala se ha ido distanciando progresivamente del interés por el análisis del espacio arquitectónico, sustituyéndose por una conceptualización abstracta de los mismos como ejemplos paradigmáticos de gestión y administración de sistemas complejos en un contexto de multiplicidad jurisdiccional (Jarach, 2001; Salter, 2008; Jensen, 2011). El problema con este tipo de metodologías es que debido a la complejidad y multiplicidad de relaciones que conlleva su estudio, las grandes jerarquizaciones espaciales que todavía conforman su organización y configuración formal terminan por difuminarse en un mar de conexiones rizomáticas espacialmente indiferenciadas, que acaban promoviendo una falsa concepción de los mismos como espacios de libertad e interconexión de flujos (Salter, 2003).

Debido a las dificultades propias de la representación gráfica que conllevaría analizar en un plano de tamaño excesivamente reducido proyectos de grandes 
aeropuertos internacionales, y con el propósito de mostrar claramente la estructura espacial básica que define el modo de funcionamiento presente en todo tipo de aeropuertos con independencia de su escala, centraremos la metodología de análisis en cinco aeropuertos de pequeña escala en los que el espacio dedicado al shopping es prácticamente inexistente, y la administración de los mismos relativamente sencilla.

Para ello, utilizaremos análisis gráficos en planta y sección realizados desde un punto de vista foucaultiano, en los que se señalarán los principales recorridos de salidas (dirección tierra-aire) con líneas discontinuas de color rojo, y los de llegadas (dirección aire-tierra) con otras de color azul. A su vez, distinguiremos tres tipos de espacios principales: espacios de uso y acceso exclusivo para los administradores y trabajadores del aeropuerto (color rojizo), espacios de acceso completamente público (color verde) y espacios de acceso para pasajeros que han pasado el control de personas y equipajes (color azul). Ello nos permitirá mostrar con un solo golpe de vista la estructuración y funcionamiento espacial de los aeropuertos analizados, y el modo en que continúan ejerciendo el tipo de poder disciplinar descrito por Foucault.

Concretamente, los aeropuertos analizados son la nueva terminal del aeropuerto San Pablo en Sevilla diseñada por Rafael Moneo (1989-1992), la nueva terminal del aeropuerto de Bilbao-Sondika diseñada por Santiago Calatrava (1999-2000), la nueva terminal del aeropuerto de Zaragoza diseñado por Luis Vidal (2005-2008) —coincidiendo con la Exposición Internacional de Zaragoza (2008)—, el aeropuerto de Lleida diseñado por Fermín Vázquez (2008-2010) y el aeropuerto de Murcia diseñado por Carlos Ferrater, Ramón Sanabria y Josep María Casadevall (2010-2012).

Las razones de su elección radican en: 1) La escala de intervención, medida por la existencia de una única terminal, un único punto de acceso al espacio 
exclusivo para viajeros y la existencia de menos de 10 brazos de salidas (fingers). 2) La homogeneidad nacional de los mismos, con el objetivo de no poder atribuir las diferencias de organización espacial a las diferencias de normativa aplicable ${ }^{6}$. 3) La proximidad cronológica de su diseño y ejecución (1989-2012), con el doble objetivo de evitar diferencias de legislación así como diferencias sustanciales en las tecnologías de edificación, vigilancia y control existentes que pudieran conllevar nuevas posibilidades espaciales ${ }^{7}$. 4) Su carácter de "arquitectura de autor", con el objetivo de evidenciar el modo en que espacios estilística y formalmente diversos mantienen un esquema esencialmente idéntico de secuencias y rituales que materializan el control disciplinar de los flujos de pasajeros.

\section{Nueva terminal del aeropuerto de Sevilla}

Al igual que la mayor parte de la obra de Moneo, el aeropuerto de Sevilla suele ser explicado tanto por el propio autor (Moneo, 2010, pp. 199-222) como por los historiadores y críticos de la arquitectura que le admiran, como un ejercicio de proyección por manipulación y composición de tipologías constructivas. En este caso, dichas tipologías serían las empleadas en la cubrición del hall de salidas mediante dos naves conformadas por sendas secuencias de cúpulas con linterna. Tipología esta que volvería a utilizar en el Museo de Arte Moderno de Estocolmo (1991-1998) y el Museo de Bellas Arte de Houston (1992-2000).

\footnotetext{
${ }^{6} \mathrm{Si}$ bien el requisito de homogeneidad nacional se podría haber realizado eligiendo aeropuertos proyectados en cualquier otro Estado, hemos elegido los de nacionalidad española debido a nuestro mayor conocimiento de la normativa aplicable en este país, regulada por el ente público AENA (Aeropuertos Españoles y Navegación Aérea).

${ }^{7}$ A este respecto, la gran cantidad de aeropuertos construidos en España a partir de la década del 90 fue una razón más en la elección de dicha nacionalidad, pues ello nos permitía disponer de una cantidad de casos suficiente a partir de los cuales poder seleccionar aquellos que cumplieran el resto de requisitos.
} 
Si bien dicha tipología constructiva proporciona un carácter estéticomonumental de tipo tradicional al edificio - construido en ladrillo- que Moon et al. (2016) no dudarían en considerar la causa última de la sensación de satisfacción que el espacio debería generar en los pasajeros, en realidad el proyecto de Moneo es uno de los que más netamente separa los tres tipos de espacio comentados: público, exclusivo para pasajeros, y exclusivo para trabajadores (Figura 2).

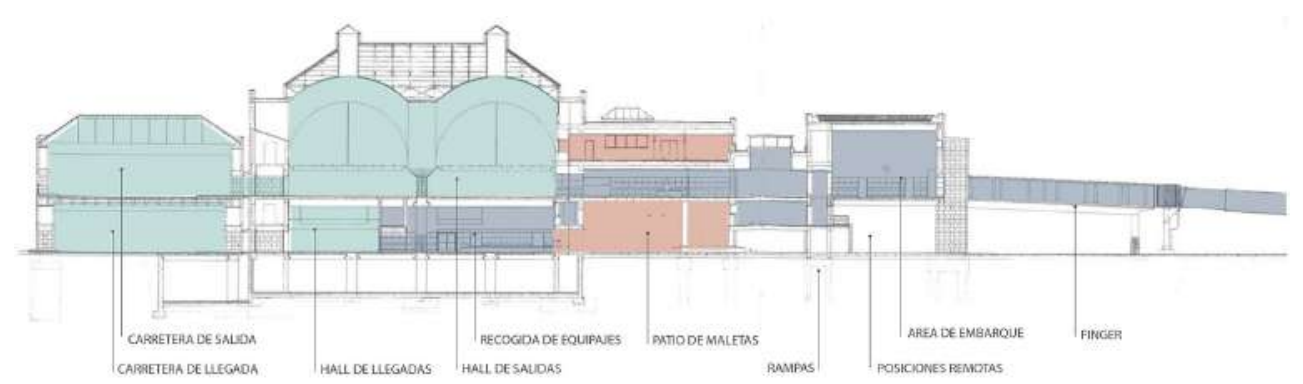

Figura 2. Sección de la terminal San Pablo - Rafael Moneo. Autor del análisis: Rubén Ruberte, mylarquitectos, 2016.

Además, el proyecto localiza la zona de administración en una posición tal que le asegura un control panóptico pleno sobre el hall de salidas. Dicho control puede apreciarse también tanto en la planta de salidas (Figura 3) como en la de llegadas (Figura 4), en las que el espacio público — considerado siempre el de mayor riesgo puesto que todavía no se ha cruzado el control de personas - resulta completamente rodeado por distintos espacios de carácter administrativo, garantizándose de este modo una sensación de vigilancia continua en sus usuarios. 


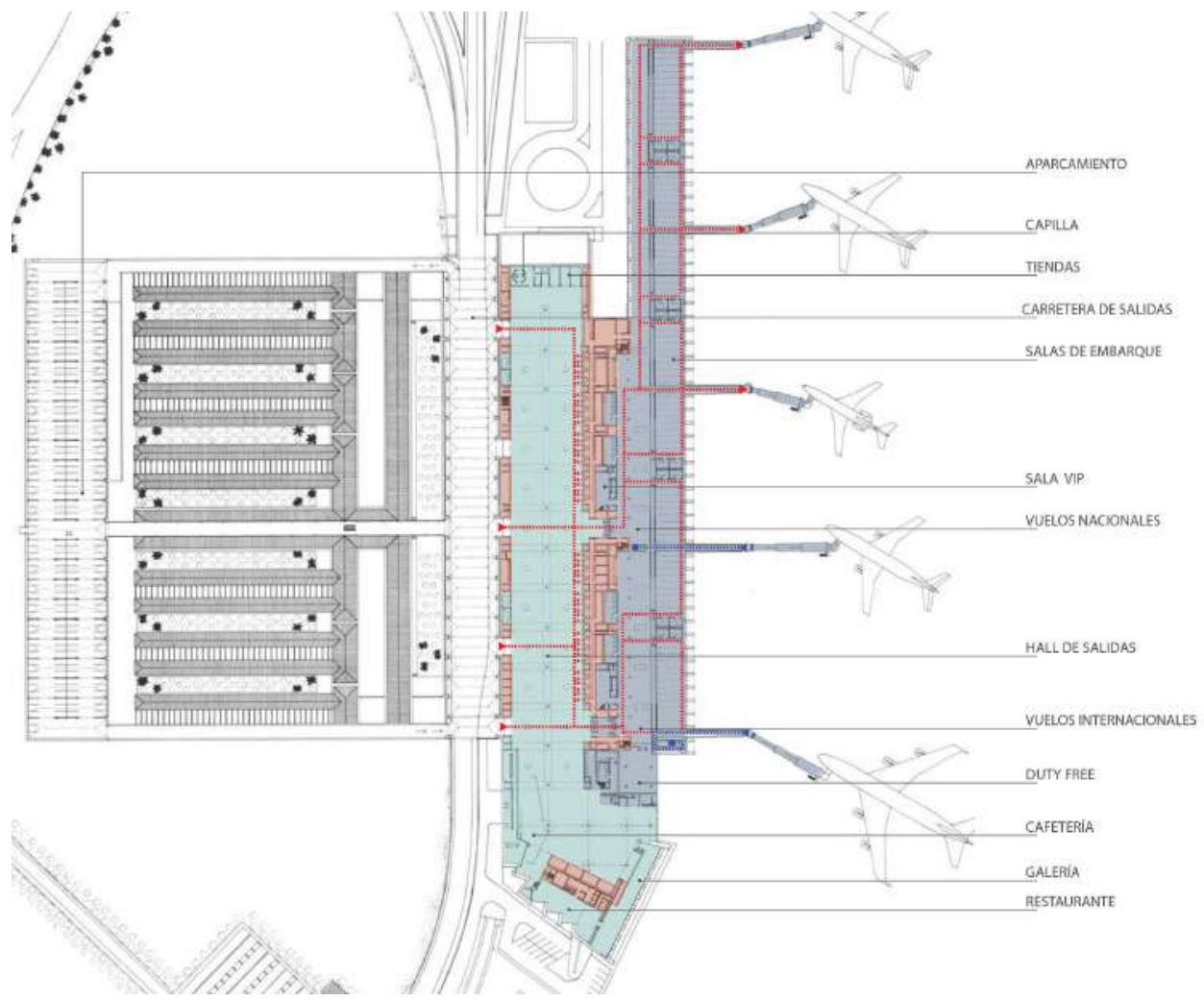

Figura 3. Planta primera (salidas) de la terminal San Pablo - Rafael Moneo. Autor del análisis: Rubén Ruberte, mylarquitectos, 2016

El hecho de que Moneo sitúe todos los pequeños espacios de ocio existentes en el programa - tienda, capilla, cafetería, restaurante y duty free- en los extremos longitudinales del edificio (ver Figura 3), promueve que el espacio destinado a estructurar las secuencias o "ritos de paso" obligatorios tanto para las salidas como para las llegadas (figuras 3 y 4 ) no sea programáticamente interrumpido en 
ningún momento por ningún tipo de flujo transversal de personas que dificulte el control de los individuos, cuyos movimientos dentro del edificio se estructuran espacialmente mediante una linealidad directa e inmediata. Debido a todo ello, el proyecto de Moneo se presenta como una formalización literal del esquema lineal de secuencias espaciales mínimas e ineludibles en cualquier aeropuerto: entrada-facturación de equipaje-control de pasajeros-embarque.

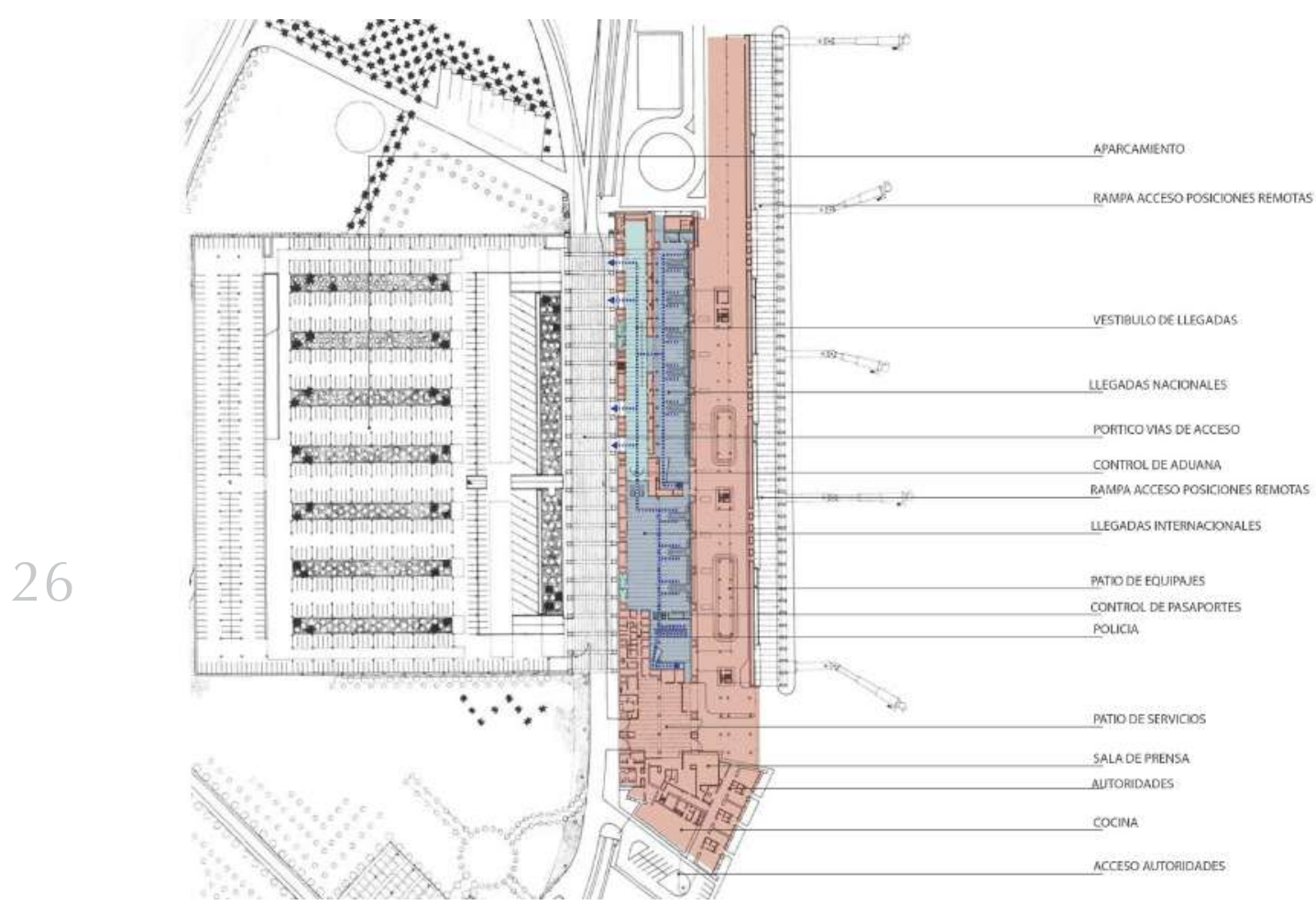

Figura 4. Planta baja (llegadas) de la terminal San Pablo - Rafael Moneo. Autor del análisis: Rubén Ruberte, mylarquitectos, 2016. 


\section{Nueva terminal del aeropuerto de Bilbao}

Con una gran similaridad formal al aeropuerto JFK de Eero Saarinen (New York) —ambos proyectos toman como inspiración la figura de un pájaro justo antes de emprender el vuelo (Figura 5) — la terminal del aeropuerto de Bilbao diseñada por Santiago Calatrava decide - a diferencia del de Moneo- dispersar y distribuir gran parte del programa administrativo del edificio entre los espacios de acceso público al mismo, situando en el punto más panóptico de todos el control de seguridad que permite el paso a la zona de embarque exclusiva para pasajeros. A este respecto, el diseño radial del hall de salidas (Figura 6) favorece el control y vigilancia del mismo desde un único punto privilegiado.

Mientras que en el aeropuerto de Sevilla el programa de ocio y consumo se situó en los extremos longitudinales del edificio con la intención de que sus flujos internos no interfirieran con los flujos de pasajeros, el proyecto de Calatrava en cambio decide dar un paso más allá y eliminarlos completamente del proyecto, configurando de este modo un espacio plenamente monofuncional al más puro estilo panóptico, rodeado y atravesado por espacios de administración.

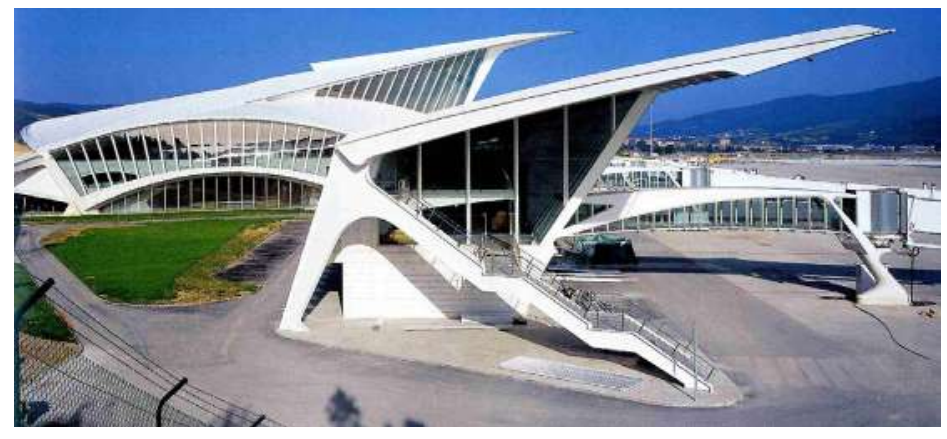

Figura 5. Vista del aeropuerto de Bilbao - Santiago Calatrava. Fuente: Wikimedia Commons. 


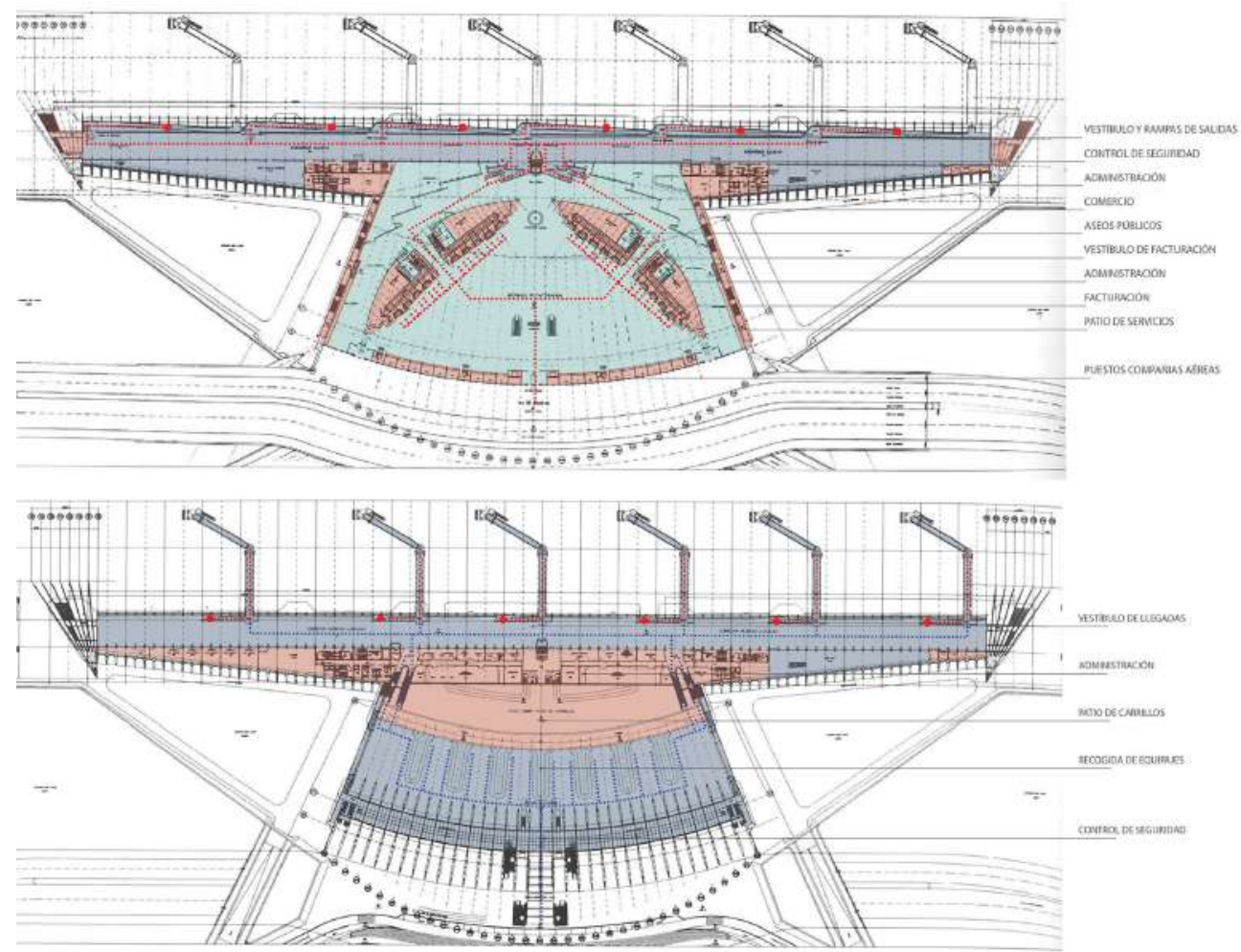

Figura 6. Plantas de salidas (arriba) y llegadas (abajo) del aeropuerto de Bilbao - Santiago Calatrava. Autor del análisis: Rubén Ruberte, mylarquitectos, 2016.

\section{Nueva terminal del aeropuerto de Zaragoza}

Pese a lo pequeño de su escala, el aeropuerto de Zaragoza concibe el hall de salidas con acceso público como un gran espacio polivalente a doble altura (Figura 7), en el que bajo una cubierta ligera que pretende imitar las ondas del 
aire (Figura 8) se distribuye mediante tabiquerías ligeras y módulos prefabricados una pequeña multitud de programas de muy variada índole como módulos de información, servicios de alquiler de coches, cafetería, restaurante, aseos, espacios de administración, stands de facturación de equipajes, mobiliario a libre disposición del usuario y/o (espacio para) tiendas (Figura 9).

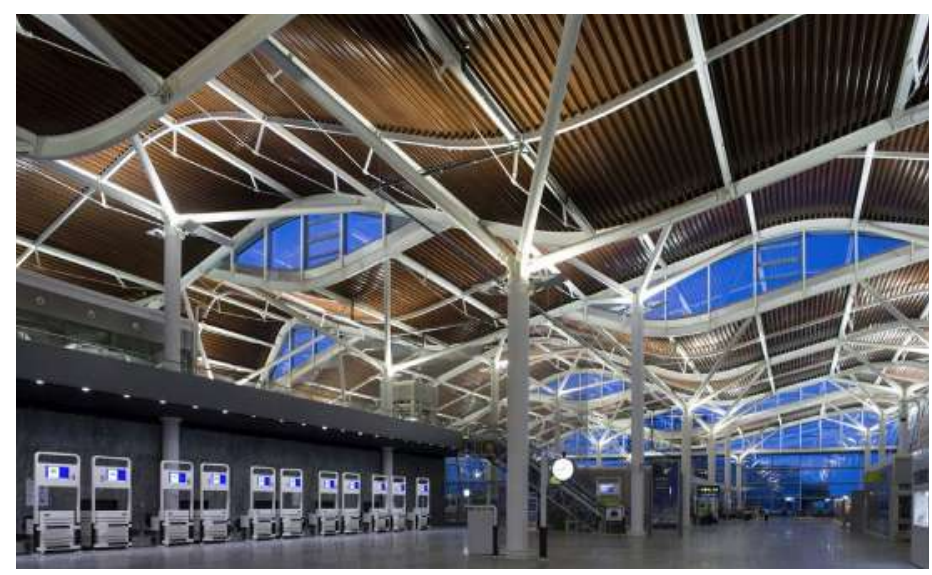

Figura 7. Vista del aeropuerto de Zaragoza - Luis Vidal. Fuente: Wikimedia Commons.

Si bien la distinción entre espacios de acceso público y espacios de acceso restringido para pasajeros vuelve a realizarse de una forma geométricamente tajante que los agrupa en dos compactos volúmenes separados por una línea continua, la concepción volumétrica del edificio como una miríada de usos bajo una cubierta espacialmente homogénea promueve que se produzca una relación visual de continuidad entre ambos espacios, lo cual ha llevado a los gestores del aeropuerto a tener que instalar una red que impida el intercambio de objetos por lanzamiento entre un espacio y otro, pues el proyecto original no aseguró la estanqueidad de ambos espacios mediante la instalación de grandes pantallas de vidrio. 


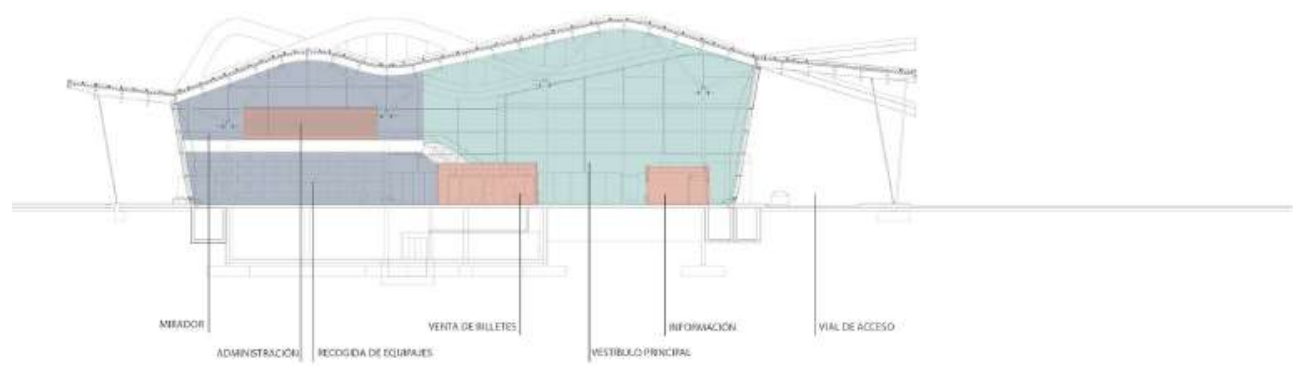

Figura 8. Sección del aeropuerto de Zaragoza - Luis Vidal. Autor del análisis: Rubén Ruberte, mylarquitectos, 2016.

Observamos de este modo cómo, aunque la intención proyectual en la organización y percepción de los espacios por parte del arquitecto se oriente a no establecer una compartimentación estanca y cerrada de los espacios a nivel volumétrico, la gestión y administración efectiva del mismo impide por principio cualquier tipo de comunicación o "retroalimentación" que introduzca elementos no previsibles en el control secuencial de los espacios. Así, aunque a nivel volumétrico pueda parecer que el proyecto es una libre meseta donde se va distribuyendo una multiplicidad de usos que recorren el espacio, a nivel de funcionamiento el análisis, categorización y compartimentación de los individuos sigue realizándose en virtud de los espacios - completamente estancos - en los que el usuario se encuentra en cada momento. 

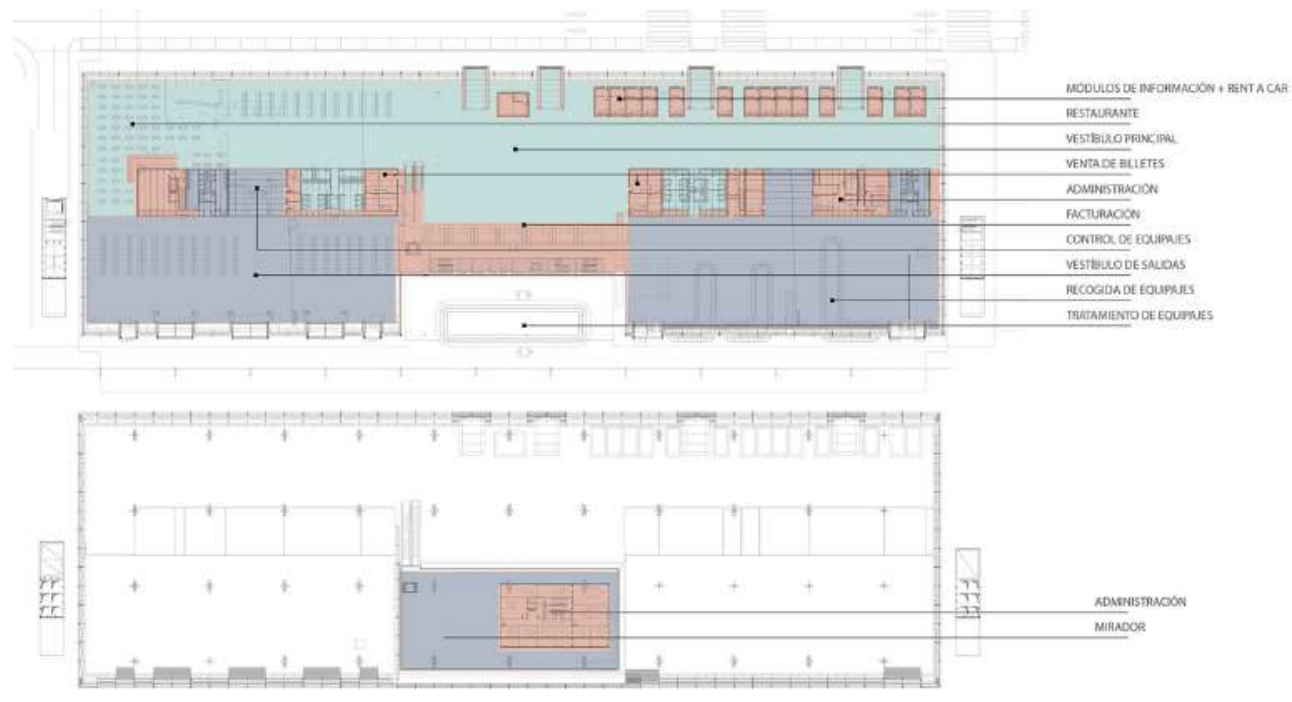

Figura 9. Plantas del aeropuerto de Zaragoza - Luis Vidal. Autor del análisis: Rubén Ruberte, mylarquitectos, 2016

\section{Aeropuerto de Lleida}

En el aeropuerto de Lleida nos encontramos una vez más con la estrategia de apostar por un fuerte componente estético, en este caso basado simplemente en el tratamiento del material y los colores de una cubierta que se convierte en el paramento de la torre de control (Figura 10), mientras la compartimentación y secuenciación espacial de los protocolos disciplinarios presentes en el edificio son llevados a su mínima expresión. 


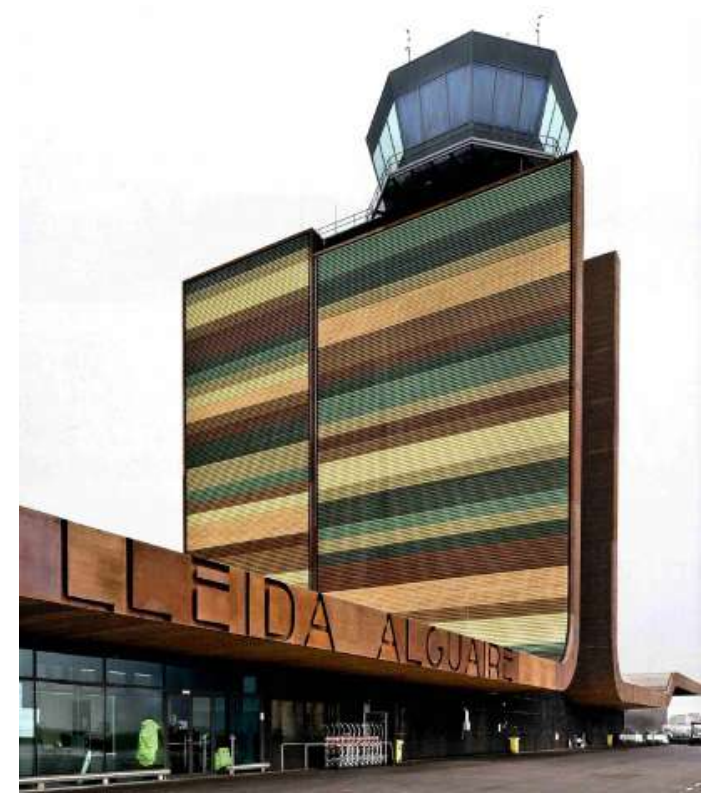

Figura 10. Vista del aeropuerto de Lleida - Fermín Vázquez. Fuente: Wikimedia Commons.

\begin{abstract}
Mientras que Moneo llevó todo el programa de ocio y consumo a los puntos extremos del edificio y Calatrava tomó la drástica medida de eliminarlos por completo del programa, el aeropuerto de Lleida diseñado por Fermín Vázquez va un paso más allá y llega hasta el extremo de situar la sala de espera en el punto más alejado del edificio, interponiendo por medio tanto los espacios de administración como el parking de los empleados (Figura 11). De este modo, en el aeropuerto de Lleida la secuencia entrada-facturación-control de pasajerosembarque es, pues, de una inmediatez tal que ni siquiera se permite un espacio de espera colindante previo al control de pasajeros que pueda perturbar la linealidad de la secuencia, iniciada con la simple entrada al edificio.
\end{abstract}


El análisis gráfico muestra claramente la rígida compartimentación de los espacios, completamente exacerbada al incluir la torre de control dentro de la volumetría del edificio, si bien razones de normativa obligan a separarla funcionalmente del resto del programa de una forma drástica mediante la inclusión de sendos vacíos a ambos lados de la misma, finalmente aprovechados como aparcamientos para el personal de servicio.

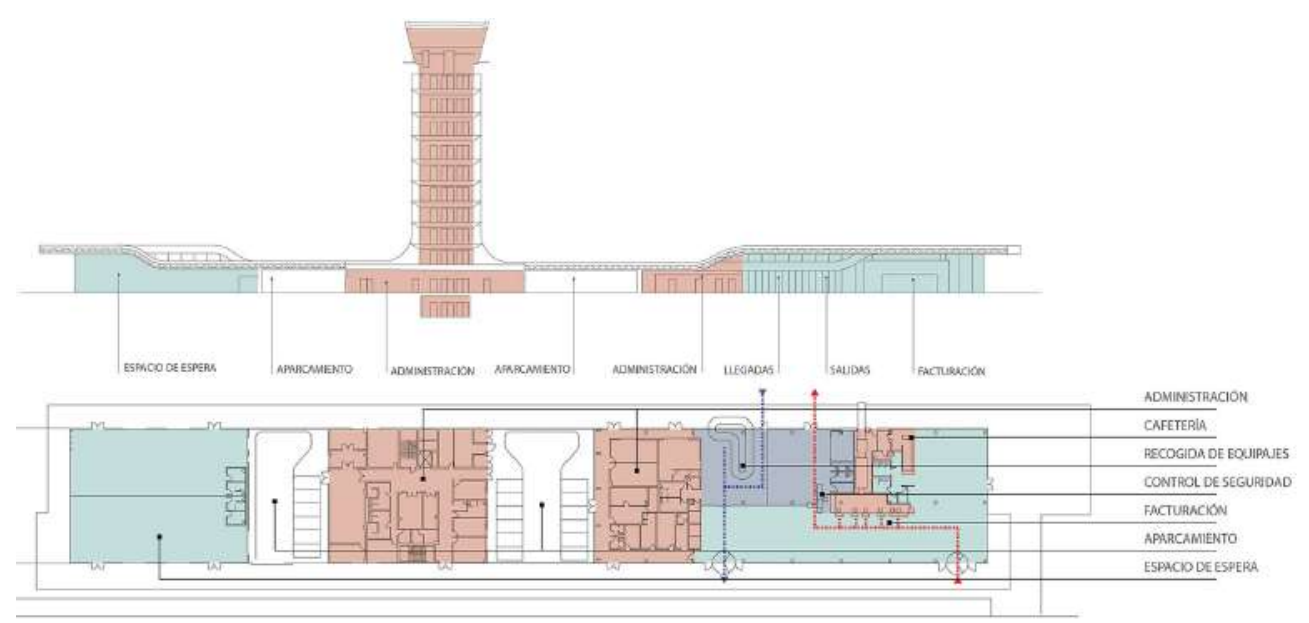

Figura 11. Planta y sección del aeropuerto de Lleida - Fermín Vázquez. Autor del análisis: Rubén Ruberte, mylarquitectos, 2016.

\section{Aeropuerto de Murcia}

Por último, en el caso del aeropuerto diseñado por Ferrater, Sanabria y Casadevall, más allá del dudoso diseño de la fachada (Figura 12), la cualidad estética del mismo ha quedado prácticamente reducida a una mera cuestión de juegos de espacios a doble o triple altura en algunos puntos del edificio (figuras 13 y 14). 


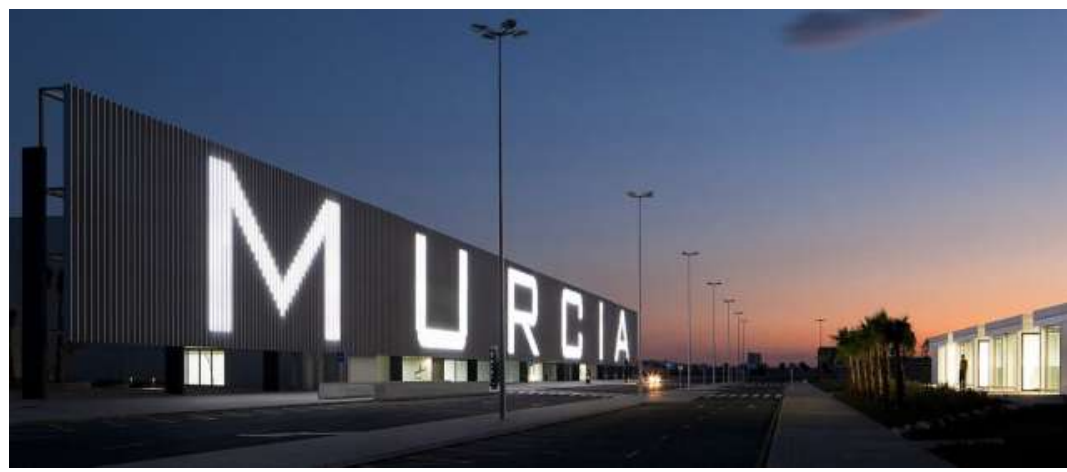

Figura 12. Vista de la fachada del aeropuerto de Murcia - Carlos Ferrater, Ramón Sanabria y Josep María Casadevall. Fuente: http://ferrater.com

En lo que se refiere al funcionamiento espacial, podemos observar un curioso cruce en altura de los recorridos de salidas y llegadas, de modo que las primeras pasan directamente de la planta baja a la planta segunda, mientras que las llegadas se realizan desde la planta primera a la planta baja o directamente desde esta última (Figura 14). A diferencia de lo que ocurre en los aeropuertos de Sevilla y Bilbao, que diferencia los recorridos de salidas y llegadas mediante su completa distribución en una única planta para cada uno, en el caso de Murcia la decisión de incluir un espacio a doble altura en planta baja de acceso exclusivo para los administradores de equipajes —o la de empeñarse en proyectar un espacio de triple altura para el hall principal- (Figura 13) complica innecesariamente la distribución de los recorridos mediante la necesidad de una planta adicional, si bien esta planta adicional no altera en modo alguno la linealidad estricta de las secuencias espaciales. La concepción volumétrica-espacial del edificio no puede alterar el carácter disciplinar de la organización secuencial del programa. Se podrán construir más plantas, pero no establecer secuencias diferentes. 


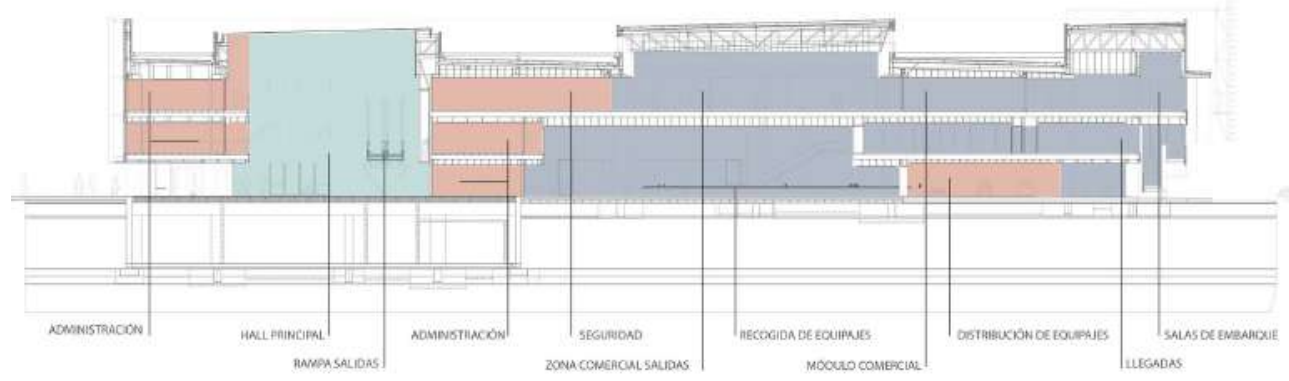

Figura 13. Sección del aeropuerto de Murcia - Carlos Ferrater, Ramón Sanabria y Josep María Casadevall. Autor del análisis: Rubén Ruberte, mylarquitectos, 2016.

Como puede verse en la sección (Figura 13), el espacio de administración se sitúa a ambos lados del hall principal, dominándolo visualmente a la perfección, mientras que el único espacio de ocio-consumo del mismo (la cafetería-restaurante) se esconde junto a la fachada de entrada para que no interrumpa ni el control visual ni los flujos principales de dicho espacio (Figura 14).

Como único elemento a destacar por contraposición al resto de proyectos analizados, merece la pena fijarse por un momento en que la secuencia principal de salidas "entrada-facturación de equipaje-control de pasajerosembarque" es completada en este caso con un espacio de shopping de paso obligado entre el control de pasajeros y las salas de embarque (Figura 14). De este modo, vemos cómo, aunque el proyecto incluye nuevos usos no estrictamente aeroportuarios, estos son plenamente integrados en el esquema funcional de los mismos, siempre consistente en una secuencia lineal obligada no atravesada por ningún tipo de recorrido alternativo. 

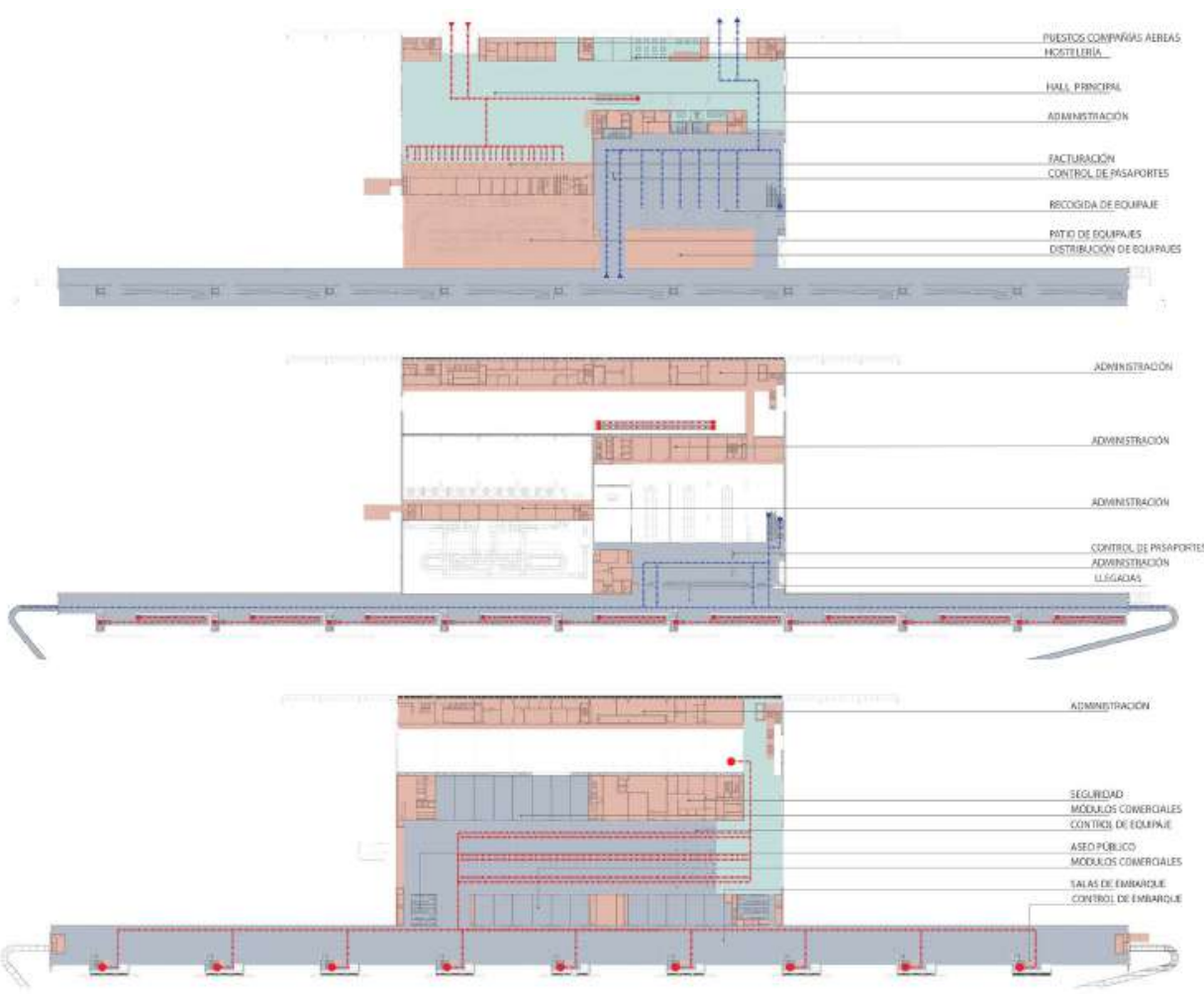

Figura 14. Plantas del aeropuerto de Murcia - Carlos Ferrater, Ramón Sanabria y Josep María Casadevall. Autor del análisis: Rubén Ruberte, mylarquitectos, 2016.

\section{Resultados y discusiones}

Los análisis realizados nos han permitido observar fácilmente cómo con independencia del diseño estético de los aeropuertos estudiados, todos ellos se adecúan estrictamente a las características espaciales de los dispositivos 
de control y vigilancia propios del poder disciplinar descritos por Foucault. A este respecto, y con la honorable excepción del aeropuerto de Zaragoza, absolutamente todos ellos marginan claramente -e incluso eliminan del programa en ciertos casos - todos aquellos espacios y/o usos de ocio-consumo que puedan conllevar una mezcla no deseada de distintos flujos de personas con el flujo principal de pasajeros, permaneciendo este último siempre dividido de forma drástica mediante la dualidad salidas-llegadas, ya sea separando estas en diferentes plantas o a través de sectorizaciones no comunicadas en la misma planta. En el caso de que dichos tipos de espacios de ocio-consumo ocupen una cantidad de superficie notable, la solución consiste en incluirlos todos juntos como una etapa aislada más de la secuencia de embarque y/o desembarque, tal y como ocurre en el aeropuerto de Murcia.

En todos los casos, se cumplen a la perfección las cinco funciones básicas del poder disciplinar descrito por Foucault: la organización espacial del programa descompone en distintas funciones los actos y operaciones a realizar (espera, facturación de equipaje, control de seguridad, shopping en caso de que exista, y embarque), los clasifica en función de objetivos concretos (evitar la multiplicidad de funciones en un mismo espacio con el objetivo de que sean más fácilmente identificables actuaciones no acordes al mismo), establece la linealidad de la secuencia óptima (primero se factura el equipaje antes de realizar el control de seguridad con el objetivo de ahorrar tiempo), fija dichos procedimientos como un protocolo interiorizado por los usuarios para futuros viajes y, finalmente, distingue entre los individuos aptos para viajar (que se adaptan a la normatividad del espacio) y los que no.

Únicamente el aeropuerto de Zaragoza tiene la virtud de haber intentado generar una "meseta" de flujos polivalentes bajo una única cubierta común, esto es, de haber intentado crear —en palabras de Deleuze y Guattari-: 
[...] una región continua de intensidades, que vibra sobre sí misma, y que se desarrolla evitando cualquier orientación hacia un punto culminante o hacia un fin exterior [de modo que] cada meseta puede leerse por cualquier sitio, y ponerse en relación con cualquier otra. (Deleuze y Guattari, 2004, p. 26)

Ahora bien, lo fundamental a tener en cuenta es que tanto en el pequeño aeropuerto de Zaragoza como en el caso de las grandes ciudades-aeropuerto de cualquier país, estas "mesetas" se producen únicamente dentro de cada uno de los tres tipos de espacios principales (público, de pasajeros y/o de administradores), no conectándose nunca entre sí puntos pertenecientes a diferentes tipos de espacios principales. Lo cual exige tener que reconocer que el carácter disciplinar del espacio domina jerárquicamente sobre el posible funcionamiento rizomático de algunos espacios aeroportuarios previamente segmentarizados.

Desde nuestro punto de vista, resulta contraproducente la elusión del análisis espacial y disciplinar que algunos investigadores han realizado en su concepción de las nuevas ciudades-aeropuerto como "una forma ubicua de diseño con el siguiente paradigma de planificación: el uso no aeronáutico del espacio aeroportuario como fuente de ingresos" (Chandu, 2016, p. 373). Concretamente, según Rem Koolhaas, este nuevo empleo de los aeropuertos como fuente de ingresos sería el punto crucial a tener en cuenta en la reconceptualización de los mismos como una nueva tipología de centros comerciales a gran escala (Koolhaas et al., 2002) propia de las sociedades móviles y conectadas en red que comenzaron a desarrollarse a partir de la década del noventa (Castells, 1996).

Por otra parte, respecto a aquellos investigadores que aún confían en el análisis gráfico de las estrategias de compartimentación y distribución funcional de la arquitectura moderna (Frampton, 2015), resulta cuanto menos sintomático que hayan eludido completamente el análisis de las tipologías aeroportuarias, 
centrándose exclusivamente en el de tipologías tradicionales como edificios cívicos, salas de conciertos, casas y pabellones, viviendas, museos, edificios de oficinas y estadios. Desde nuestro punto de vista, ello se debe a que los análisis funcionales comentados por Frampton no se han realizado desde una concepción que considere la arquitectura como un dispositivo de control y vigilancia del poder disciplinar, sino únicamente como medios para mostrar más rápidamente la organización formal del espacio arquitectónico según espacios principales ("servidos"), comunicaciones y espacios secundarios ("servidores").

En el caso de Frampton, la jerarquización y distribución funcional del espacio son interpretadas únicamente como signo de ordenación "racional" del mismo, pero sin incluir ningún tipo de reflexión sobre las relaciones sociales de poder que ello conlleva, de modo que la jerarquización formal del espacio continúa siendo concebida por la mayor parte de la disciplina arquitectónica como una cualidad meramente compositiva o estética del edificio, hasta el punto de que será "buena arquitectura" cuando tenga una estructuración espacial claramente perceptible que la haga racionalmente comprensible.

Incluso, en el caso de aquellos arquitectos que iniciaron sus teorías del proyecto arquitectónico desde posiciones claramente antiformalistas (Tschumi, 1996; Koolhaas, 2004) o diagramáticas (Eisenman 2000), el carácter organizativo del programa a cumplir siempre determinó el tipo de secuencias o conexiones espaciales a establecer en el proyecto, con el objetivo de producir un tipo de (comportamiento del) usuario concreto (León y Castejón, 2020).

Moon et al. (2016) podrán considerar positivamente las características estéticas de un aeropuerto en tanto que elemento primario que favorece la satisfacción de sus usuarios, si bien desde nuestro punto de vista $-y$ a la luz de los análisis realizados - únicamente podemos considerar dicho aspecto estético 
de dos maneras: 1) Como una máscara que intenta ocultar y embellecer el carácter abiertamente carcelario de los aeropuertos (Sevilla, Bilbao, Lleida o Murcia), o 2) Como una ilusión engañosa que pretende hacer creer que una tipología arquitectónica disciplinar como el aeropuerto es capaz de funcionar espacialmente como una meseta abierta para el libre entrecruzamiento de flujos y recorridos (Zaragoza).

A este respecto, el análisis de la tipología aeroportuaria realizado en este artículo ha mostrado el modo en que la arquitectura continúa funcionando como un dispositivo espacial de poder con independencia de su calidad estético-antropológica y los supuestos beneficios psicológicos que pueda aportar la percepción fenomenológica de sus espacios, pues el carácter disciplinar del espacio no radica en su consideración estético-fenomenológica sino en la organización y control de los flujos de la población y la movilidad espacial de los individuos.

\section{Conclusiones}

Si bien la concepción y realización de la investigación conducente a la redacción de este artículo fue desarrollada con anterioridad al inicio de la pandemia de Covid-19 y la declaración de los estados de alarma consecuentes, los acontecimientos posteriores a la misma orientados al control de la movilidad de personas han dado muestras renovadas de la extremada eficacia de la tipología aeroportuaria como dispositivo fronterizo basado en una gestión disciplinar del espacio.

Mientras que el control de la movilidad terrestre resulta problemático debido a la gran cantidad de espacio abarcado y la falta de medios técnicos y humanos para su completa vigilancia, el tráfico aéreo resulta absolutamente controlable por parte de los poderes públicos y privados que lo gestionan. Si bien pudiera 
parecer que en un mundo globalizado donde la movilidad individual se incrementa exponencialmente, la capacidad de control disciplinar de dichos individuos debería reducirse al mínimo, la realidad es precisamente la contraria: una vez que la movilidad aérea se vuelve hegemónica, la capacidad de control disciplinar aumenta de forma directamente proporcional.

Cuando la calle era la principal autopista para el transporte de personas y mercancías, la toma de las mismas (mediante barricadas o comunas) todavía tenía una efectividad política cuyo alcance afectaba al conjunto del territorio estatal. En el siglo XXI en cambio, una vez que el tráfico aéreo ha tomado el relevo de dichas autopistas, la toma de las calles queda reducida a una mera eficacia simbólica sin capacidad para paralizar y/o poner en crisis el funcionamiento de la red estatal de infraestructuras de movilidad.

En este sentido, los aeropuertos y la movilidad aérea que se gestiona con ellos no deberían verse como una tecnología que permite únicamente un incremento de nuestra libertad (de movimiento) y autodeterminación, sino todo lo contrario. Tal y como sostenía Paul Virilio (2006) en la cita comentada al principio de este artículo, "el auge del totalitarismo va de la mano con el desarrollo del control del Estado sobre la circulación de las masas" (p. 41).

Este carácter totalitario y disciplinar de los aeropuertos como dispositivos paradigmáticos para el control de la movilidad quedó claramente patente en el territorio español cuando, a raíz de una huelga "espontánea" (no previamente convocada) de controladores aéreos en 2010, el Gobierno de España declaró el entonces único Estado de alarma en la historia de su democracia, con el objetivo de que el Ejército pudiera tomar el control de los aeropuertos civiles, abriendo diligencias a los controladores por un posible delito de sedición, de forma simultánea a los 442 expedientes "disciplinarios" abiertos por AENA, la agencia encargada de la gestión de los Aeropuertos Españoles y Navegación Aérea. 
Tanto el Estado de alarma declarado en 2020 a raíz de la pandemia de Covid-19 como el declarado a raíz de la huelga de controladores de 2010, ponen de relevancia el carácter totalitario y disciplinar del control de la movilidad en el siglo XXI. El análisis realizado en este artículo ha tratado de mostrar el modo en que la configuración espacial de las principales infraestructuras arquitectónicas con las que se gestiona dicho tipo de movilidad funciona como una herramienta directamente subsidiaria de dicha gestión disciplinaria del poder. En consecuencia, los arquitectos podrán desarrollar su creatividad e innovación únicamente en aquellos ámbitos y/o facetas del espacio aeroportuario que no afecten en lo más mínimo a la secuenciación y control de los espacios mediante los que se clasifica, vigila, homogeniza y normaliza (la seguridad de) los movimientos de pasajeros y mercancías.

\section{Referencias}

Aaltola, M. (2005). The international airport: the hub-and-spoke pedagogy of the American empire. Global Networks, 5, 261-278.

Adey, P. (2002). Secured and Sorted Mobilities: Examples From the Airport. Surveillance \& Society, 1(4), 500-519. https://doi.org/10.24908/ss.v1i4.3333

Adey, P. (2004). Surveillance at the Airport: Surveilling Mobility/Mobilising Surveillance. Environment and Planning A: Economy and Space, 36(8), 1365-1380. https://doi. org/10.1068/a36159

Adey, P. (2006). Airports and air-mindedness: Spacing, timing and using the Liverpool Airport, 1929-1939. Social \& Cultural Geography, 7(3), 343-363. https://doi. org/10.1080/14649360600714998

Adey, P. (2007a). Airports for Children: Mobility, Design and the Construction of an Airport Education. Built Environment, 33(4), 417-429.

Adey, P. (2007b). May I Have Your Attention': Airport Geographies of Spectatorship, Position, and (Im)mobility. Environment and Planning D-society \& Space, 25(3), 515-536.

Adey, P. (2008a). Airports, Mobility and the calculative architecture of affective control. Geoforum, 39(1), 438-451. https://doi.org/10.1016/j.geoforum.2007.09.001 
Adey, P. (2008b). Architectural geographies of the airport balcony: Mobility, sensation and the theatre of flight. Geografiska Annaler: Series B, Human Geography, 90(1), 29-47. https://doi. org/10.1111/j.1468-0467.2008.00274.x

Adey, P. (2008c). Mobilities and Modulations: The airport as a difference machine. En M. B. Salter (Ed.), Politics at the airport (pp. 145-167). University of Minnesota Press.

Adey, P. (2009). Facing airport security: Affect, biopolitics, and the preemptive securitisation of the mobile body. Environment and Planning D: Society and Space, 27(2), 274-295.

Adey P. (2010). Aerial Life. Wiley-Blackwell.

Augé, M. (1995). Non-Places: Introduction to an Anthropology of Supermodernity. Verso.

Blow, Ch. J. (1991). Airport Terminals. Butterworth Architecture Library of Planning and Design.

Carter, A. B. (2001-02). The Architecture of Government in the Face of Terrorism. International Security, 26(3), 5-23.

Castells, M. (1996). The Rise of the Network Society. Blackwell.

Chandu, A. (2016). The world's first purpose-built Airport City: Melbourne Airport, Tullamarine. Planning Perspectives, 32(3), 373-400. https://doi.org/10.1080/02665433.2016.1262787

Crang, M. (2002). Between places: producing hubs, flows, and networks. Environment and Planning A, 34(3), 569-574.

Deleuze, G. y Guattari, F. (2004). Mil mesetas. Capitalismo y esquizofrenia. Pre-Textos.

Díaz, C. B. (2014). Arquitectura de aeropuertos: cuatro ejemplos de terminales aeroportuarias de la década de 1930. Cuaderno de Notas, 15, 18-36. https://doi.org/10.20868/cn.2014.2955

Edwards, B. (1998). The Modern Terminal. New approaches to airport architecture. Routledge.

Eisenman, P. (2000). Diagram Diaries. Thames \& Hudson.

Frampton, K. (2015). A Genealogy of Modern Architecture. Comparative Critical Analysis of Built Form. Lars Müller Publishers.

Foucault, M. (2005). Vigilar y Castigar. Siglo XXI.

Foucault, M. (2006). Seguridad, territorio y población: Curso en el Collège de Francia (19771978). Fondo de Cultura Económica. 
Fuller, G. y Harley, R. (2005). Aviopolis: A Book about Airports. Black Dog Publishing.

Gordon, A. (2004). Naked Airport: A Cultural History of the World's Most Revolutionary Structure. Henry Holt.

Gottdiener, M. (2001). Life in the Air: Surviving the New Culture of Air Travel. Rowman and Littlefield.

Hirsh, M. (2016). Airport Urbanism. Infrastructure and Mobility in Asia. University of Minnesota Press.

Jarach, D. (2001). The evolution of airport management practices: towards a multi-point, multiservice, marketing-driven firm. Journal of Air Transport Management, 17, 119-125.

Jensen, A. (2011). Mobility, space and power: on the multiplicities of seeing mobility. Mobilities, 6(2), 255-271.

Kasarda, J. (2008). Airport Cities. Insight Media.

Koolhaas, R. (2004). Content. Taschen.

Koolhaas, R. et al. (2002). The Harvard Design School Guide to Shopping / Harvard Design School Project on the City 2. Taschen.

Leary, W. M. (Ed.). (1995). From Airships to Airbus: The History of Civil and Commercial Aviation, Volume 1: Infrastructure and Environment. Smithsonian Institution Press.

León, J. y Castejón, J. M. (2020). Rituales de libertad. Disciplina y biopolítica de la arquitectura docente. BAc, Boletín Académico, 10, 2020, 62-83. https://doi.org/10.17979/ bac.2020.10.0.5747

Lyon, D. (2001). Surveillance Society: Monitoring everyday life. Open University Press.

Lyon, D. (2003). Airports as Data Filters: Converging Surveillance Systems after September 11th. Information, Communication and Ethics in Society, 1(1), 13-20.

Moneo, R. (2010). Apuntes sobre 21 obras. Gustavo Gili.

Pascoe, D. (2001). Airspaces. Reaktion Books.

Pearman, H. (2004). Airports. A century of architecture. Harry N. Abrams.

Salter, M. (2003). Rites of Passage: The passport in international relations. Lynne Rienner. 
Salter, M. B. (2008). The global airport: Managing space, speed, and security. En D. Salter (Ed.), Politics at the Border (pp. 1-28). University of Minnesota Press.

Tschumi, B. (1996). Architecture and Disjunction. The MIT Press.

Virilio, P. (1984). L'espace Critique. Christian Bourgois Editeur.

Virilio, P. (2006). Speed and Politics. Semiotext(e).

Wolf, P. J. (2001). Authority: delegation. International Encyclopedia of the Social and Behavioral Sciences, 972-978.

Zukowsky, J. (Ed.). (1996). Building for Air Travel: Architecture and design for commercial aviation. The Art Institute of Chicago/Prestel-Verlag.

Cómo citar: León Casero, J. (2021). El aeropuerto como dispositivo disciplinar para el control de la movilidad. Revista KEPES, 18(24), 11-45. https://doi.org/10.17151/kepes.2021.18.24.2 